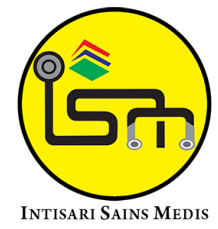

Published by Intisari Sains Medis

\title{
Karakteristik pasien fraktur kruris di RSUD Sanjiwani Gianyar tahun 2020
}

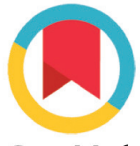

CrossMark

\author{
Gede Agastya Pracheta Ewari ${ }^{*}$, Yoga Premana ${ }^{2}$
}

\section{ABSTRACT}

Background: The location of the most fractures in traffic accident victims is the lower extremity bone. Data from the Basic Health Research (Riskesdas) also shows that fractures in the lower extremities due to traffic accidents have the highest prevalence among other fractures. Cruris fractures generally occur as a result of high-energy trauma such as a traffic accident or low-energy torsional trauma. The increase in cases of trauma, especially traffic accidents cause an increase in the incidence of tibial and fibular fractures. This study aims to determine the prevalence and characteristics of cruris fractures at the Sanjiwani Hospital, Gianyar in 2020.

Methods: The design of this study was retrospective descriptive using 30 samples of cruris fractures taken from secondary data from patient medical records at the Sanjiwani Hospital, Gianyar. The variables of this study included gender, age, cause of fracture and type

of cruris fracture. Data analysis using SPSS software. Results: The most common fractures of the tibia and fibula occurred in male patients (56\%). The age group most frequently experiencing cruris fractures is the adult age (18-59 years). The most common cause of cruris fractures was traffic accidents as many as 19 people (64\%). The most common type of cruris fracture found in this study was a fracture of the tibia fibula as many as 21 people (70\%).

Conclusion: The most common cruris fractures are tibia and fibula fractures in men, with the most common cause of traffic accidents. This study is expected to be able to become a basic data material for conducting a wider study on the prevalence and characteristics of cruris fractures in Bali, so that the public can be more aware of the incidence of fractures that still occur frequently.
${ }^{1}$ Fakultas Kedokteran Universitas Udayana, Denpasar, Bali, Indonesia;

${ }^{2}$ SMF IImu Bedah, Rumah Sakit Umum Daerah Sanjiwani, Gianyar, Bali, Indonesia;

\section{*Korespondensi:}

Gede Agastya Pracheta Ewari;

Fakultas Kedokteran Universitas Udayana, Denpasar, Bali, Indonesia;

agastyaprachetaa@yahoo.com

Diterima: 14-08-2021

Disetujui: 20-09-2021

Diterbitkan: 06-10-2021

Keywords: epidemiology, characteristics, cruris fracture, fibula fracture, tibial fracture.

Cite This Article: Ewari, G.A.P., Premana, Y. 2021. Karakteristik pasien fraktur kruris di RSUD Sanjiwani Gianyar tahun 2020. Intisari Sains Medis 12(3): 689-693. D0l: 10.15562/ism.v12i3.1141

\section{ABSTRAK}

Latar belakang: Lokasi fraktur terbanyak pada korban meninggal kecelakaan lalu lintas adalah pada tulang bagian ekstremitas bawah. Data dari Riset Kesehatan Dasar (Riskesdas) juga menunjukkan bahwa fraktur pada ekstremitas bawah akibat kecelakaan lalu lintas memiliki prevalensi yang paling tinggi diantara fraktur lainnya. Fraktur kruris pada umumnya terjadi akibat trauma dengan energi tinggi seperti kecelakan lalu lintas atau trauma torsional energi rendah. Peningkatan kasus trauma, terutama kecelakaan lalu lintas menyebabkan peningkatan insidens fraktur tibial dan fibular. Penelitian ini bertujuan untuk mengetahui prevalensi dan karakteristik dari fraktur kruris di RSUD Sanjiwani Gianyar pada tahun 2020.

Metode: Rancangan penelitian ini adalah deskriptif retrospektif dengan menggunakan 30 sampel fraktur kruris yang diambil dari data sekunder rekam medis pasien di RSUD Sanjiwani Gianyar. Variabel penelitian ini meliputi jenis kelamin, usia, penyebab fraktur dan jenis fraktur kruris. Analisa data menggunakan perangkat lunak SPSS.

Hasil: Fraktur tibia dan fibula paling banyak terjadi pada pasien laki - laki (56\%). Kelompok usia yang paling sering mengalami fraktur kruris adalah usia dewasa (18 - 59 tahun). Penyebab terbanyak fraktur kruris adalah kecelakaan lalu lintas sebanyak 19 orang (64\%). Jenis fraktur kruris tersering yang ditemukan pada penelitian ini adalah fraktur tibia fibula sebanyak 21 orang (70\%).

Simpulan: Fraktur kruris paling banyak didapatkan adalah fraktur tibia dan fibula pada laki-laki, dengan penyebab tersering kecelakaan lalu lintas. Penelitian ini diharapkan mampu menjadi bahan data dasar untuk dilakukannya penelitian lebih luas mengenai 
prevalensi dan karakteristik fraktur kruris di Bali, kejadian fraktur yang masih sering terjadi. sehingga masyarakat dapat lebih waspada mengenai

Kata kunci: epidemiologi, fraktur kruris, fraktur fibula, fraktur tibia, karakteristik.

Sitasi Artikel ini: Ewari, G.A.P., Premana, Y. 2021. Karakteristik pasien fraktur kruris di RSUD Sanjiwani Gianyar tahun 2020. Intisari Sains Medis 12(3): 689-693. D0I: 10.15562/ism.v12i3.1141

\section{PENDAHULUAN}

Fraktur merupakan suatu diskontinuitas pada tulang baik sebagian atau seluruhnya, di satu tempat atau beberapa tempat yang sering diikuti kerusakan jaringan sekitarnya. Pada fraktur dapat ditemukan putusnya kontinuitas tulang, tulang rawan sendi, tulang rawan epifisis, baik yang bersifat total maupun parsial. Fraktur sering disebabkan oleh trauma dimana terdapat tekanan yang berlebihan pada tulang, baik berupa trauma langsung dan trauma tidak langsung. ${ }^{1}$ Pada dewasa muda, fraktur disebabkan oleh trauma berenergi tinggi, sedangkan pada usia tua fraktur lebih banyak disebabkan oleh trauma berenergi rendah dan osteoporosis. Manifestasi klinis fraktur dapat berupa nyeri, hilangnya fungsi, deformitas, pemendekan ekstremitas, krepitus, pembengkakan lokal, dan perubahan warna. Penyebab fraktur dikelompokan menjadi peristiwa patologis dan peristiwa trauma. $^{2}$

Penelitian Riandini pada tahun 2015 menunjukan bahwa lokasi patah tulang terbanyak pada korban meninggal kecelakaan lalu lintas adalah pada tulang bagian ekstremitas bawah. ${ }^{3}$ Dari sekian banyak kasus fraktur di Indonesia, fraktur pada ekstremitas bawah akibat kecelakaan lalu lintas memiliki prevalensi yang paling tinggi diantara fraktur lainnya yaitu sekitar 46,2\%. ${ }^{3}$ Salah satu jenis fraktur yang paling sering terjadi pada ekstremitas bawah adalah fraktur kruris. Fraktur kruris merupakan suatu istilah untuk patah tulang tibia dan fibula yang biasanya terjadi pada bagian proksimal, diafisis, atau persendian pergelangan kaki. Fraktur pada lokasi ini sangat sering dijumpai pada kecelakaan lalu lintas. Menurut data dari Depkes RI (2011), dari 45.987 orang dengan kasus fraktur ekstremitas bawah akibat kecelakaan, 14.027 orang mengalami fraktur kruris, 3.775 orang mengalami fraktur tibia, 970 orang mengalami fraktur pada tulang - tulang kecil di kaki dan 336 orang mengalami fraktur fibula. ${ }^{4}$ Dalam fungsinya, tibia berperan dalam menopang berat tubuh, sedangkan fibula berperan terutama dalam perlekatan otot - otot disekitarnya. Tibia terletak pada sisi anteromedial dari tungkai dan merupakan tulang terbesar kedua pada tubuh manusia. Pada bagian proximal, tulang tibia melebar membentuk dua bulatan yang disebut kondilus medialis dan kondilus lateralis yang menggantung korpus di medial, lateral, dan posterior, lalu membentuk permukaan artikular superior yang relatif rata atau plateau tibia. ${ }^{1}$

Fraktur kruris pada umumnya terjadi akibat trauma dengan energi tinggi seperti kecelakan lalu lintas atau trauma torsional energi rendah. Jaringan kulit dan subkutan pada bagian anterior dan medial tibia sangat tipis, akibatnya fraktur pada ekstremitas bawah pada umumnya bersifat fraktur terbuka. Karena struktur ini pula, jaringan ikat yang tipis tersebut dapat terganggu. Di sisi lain, fibula sebagian besar ditutupi oleh jaringan ikat kecuali pada bagian malleolus lateral. Secara anatomis, saraf peroneus umum menyilang leher fibular, sehingga saraf ini cenderung untuk mengalami cedera akibat fraktur leher fibular, tekanan bebat atau selama prosedur pembedahan. ${ }^{5}$ Kerusakan saraf peroneus ini akan menyebabkan komplikasi seperti drop foot dan gangguan sensasi. Komplikasi lain seperti delayed union, nonunion dan artritis juga sering terjadi, terutama pada tulang tibia, fraktur non union lebih sering terjadi. Amputasi pada umumnya terjadi karena trauma jaringan ikat yang parah, gangguan neurovaskular, cedera arteri popliteal, sindrom kompartemen atau infeksi seperti gangrene atau osteomyelitis. Cedera arteri popliteal inilah yang yang berpotensi membahayakan ekstremitas. ${ }^{6}$
Apabila terjadi fraktur pada kedua tulang tibia dan fibula, penanganannya diutamakan untuk reduksi tulang tibia. Angulasi residu atau rotasi minimal pada lokasi fraktur akan menyebabkan deformitas nyata dan perlu dicegah selama terapi. Manajemen fraktur kruris bervariasi, tergantung dari jenis fraktur yang terjadi. Penatalaksanaan harus dilakukan secara komprehensif, baik dengan tindakan operatif maupun non operatif. Prosedur plating merupakan pilihan utama stabilisasi fraktur ini dan memastikan reduksi serta fiksasi terjadi secara akurat. Namun, perlu diperhatikan risiko - risiko komplikasi yang berkaitan dengan prosedur ini. ${ }^{1,2}$ Keberhasilan penatalaksanaan fraktur kruris membutuhkan waktu yang cukup lama dan kontribusi pasien dalam menjalani fisioterapi. Selain itu penanganan awal harus dilakukan dengan cepat dan tepat untuk mencegah komplikasi yang dapat berakibat fatal. ${ }^{7,8}$ Dengan melihat angka insiden yang tinggi dan masih jarang penelitian mengenai karakteristik pasien fraktur kruris ini, maka peneliti tertarik untuk meneliti gambaran karakteristik pasien fraktur kruris di RSUD Sanjiwani Gianyar.

\section{METODE}

Penelitian ini menggunakan rancangan penelitian deskriptif-retrospektif untuk mengidentifikasi data pasien fraktur kruris di RSUD Sanjiwani Gianyar pada tahun 2020. Sampel penelitian ini diperoleh dengan total sampling dari data sekunder rekam medis pasien yang di rawat inap di RSUD Sanjiwani Gianyar dengan diagnosis fraktur kruris pada selama bulan Februari - Mei 2020. Jumlah sampel yang didapatkan sebanyak 30 sampel. Variabel penelitian ini meliputi jenis kelamin, usia, penyebab fraktur dan jenis fraktur kruris yang terjadi. Seluruh data akan dianalisis 
secara univariat menggunakan perangkat lunak SPSS.

\section{HASIL}

Pada penelitian ini didapatkan 30 sampel penelitian pasien dengan fraktur kruris. Karakteristik sampel dibagi berdasarkan jenis kelamin, usia, penyebab fraktur dan jenis fraktur kruris.

Berdasarkan data dari tabel 1, jenis kelamin sampel terbanyak adalah laki laki dengan jumlah sebesar 17 orang (56\%), sedangkan jumlah sampel penelitian yang berjenis kelamin perempuan adalah sebesar 13 orang (44\%). Usia sampel pada penelitian ini dikategorikan menjadi usia muda untuk pasien berusia $<18$ tahun sebanyak 4 orang (14\%), usia dewasa berusia 18 - 59 tahun sebanyak 17 orang (56\%) dan usia lanjut sebanyak 9 orang (30\%). Dapat disimpulkan bahwa, pada penelitian ini pasien dengan fraktur kruris paling banyak ditemukan pada kelompok usia dewasa (18 - 59 tahun). Penyebab terbanyak fraktur kruris pada penelitian ini adalah kecelakaan lalu lintas sebanyak 19 orang (64\%). Jenis fraktur kruris tersering yang ditemukan pada penelitian ini adalah fraktur tibia - fibula sebanyak 21 orang (70\%), diikuti dengan fraktur tibia sebanyak 8 orang (27\%) dan fraktur fibula sebanyak 1 orang (3\%).

\section{PEMBAHASAN}

Saat ini, cedera merupakan salah satu beban kesehatan secara global yang mencakup sekitar 90\% kejadian trauma yang berkaitan dengan peningkatan mortalitas, dimana pada tahun 2030 cedera diperkirakan akan menjadi 4 besar penyebab kematian terbanyak. ${ }^{9}$ The Global Burden for Disease memprediksi bahwa kecelakaan lalu lintas akan berada pada posisi ke 6 sebagai penyebab kematian terbanyak pada tahun 2020 dan akan terus meningkat apabila sistem rambu - rambu keselamatan di jalan tidak diperbaiki. Sebuah studi menunjukkan bahwa pada negara - negara berpendapatan rendah dan sedang cedera akibat kecelakaan lalu lintas menyumbang sekitar 30 - 86\% kasus trauma di rumah sakit, hal ini terutama terjadi karena penggunaan kendaraan roda dua sebagai moda transportasi utama tanpa perbaikan infrastruktur

Tabel 1. Distribusi profil pasien fraktur femur.

\begin{tabular}{lcc}
\hline \multicolumn{1}{c}{ Profil Pasien } & Jumlah $(\mathbf{n = 3 0 )}$ & Presentase (\%) \\
\hline Jenis Kelamin & & \\
Laki - laki & 17 & $56 \%$ \\
Perempuan & 13 & $44 \%$ \\
Umur & & \\
$<18$ & 4 & $14 \%$ \\
$18-59$ & 17 & $56 \%$ \\
$>59$ & 9 & $30 \%$ \\
Penyebab & & \\
Kecelakaan Lalu Lintas & 19 & $64 \%$ \\
Terjatuh & 11 & $36 \%$ \\
Jenis Fraktur & & \\
Tibia-fibula & 21 & $70 \%$ \\
Tibia & 8 & $27 \%$ \\
Fibula & 1 & $3 \%$ \\
\hline
\end{tabular}

jalan maupun rambu - rambu lalu lintas. ${ }^{9}$ Studi Pan dkk. menemukan bahwa lokasi terjadinya fraktur tersering akibat kecelakaan lalu lintas adalah bagian tulang tengkorak, diikuti dengan tulangtulang pada ekstremitas bawah dan ekstremitas atas. ${ }^{10}$ Penelitian lain di Afrika menunjukkan bahwa fraktur yang paling sering terjadi akibat kecelakaan lalu lintas adalah fraktur pada tibia dan fibula. ${ }^{11}$ Di Indonesia, data dari Riset Kesehatan Dasar (RISKESDAS) menunjukkan bahwa fraktur pada ekstremitas bawah akibat kecelakaan memiliki prevalensi tertinggi dibandingkan dengan fraktur lainnya, yaitu sebesar 46,2\%. Dari sebanyak 45.987 kasus fraktur pada ekstremitas bawah akibat kecelakaan, sekitar 14.027 kasus merupakan fraktur kruris, 3.775 kasus fraktur tibia dan 336 kasus fraktur fibula. ${ }^{4}$

Tulang tibia merupakan salah satu tulang penahan berat tubuh dan fraktur tibia pada umumnya berasosiasi dengan tulang fibula karena energi yang ditransmisikan melalui interosseous membrane. Mekanisme utama terjadinya fraktur tibia dan fibula dibagi menjadi 2 yaitu, secara langsung akibat cedera berenergi tinggi seperti kecelakaan lalu lintas maupun secara tidak langsung akibat cedera energi rendah seperti jatuh atau cedera karena olahraga. Secara anatomis, tulang tibia dan fibula berartikulasi pada sindemosis tibia-fibula proksimal. Fraktur pada tibia dapat terjadi pada beberapa lokasi meliputi tibial plateau, tuberkulus tibia, eminensia tibia, proksimal tibia, fraktur shaft tibia dan fraktur pilon tibia. Diketahui bahwa shaft tibia dan fibular paling sering mengalami fraktur bila dibandingkan dengan tulang panjang lainnya. Hal ini dikarenakan periosteum pada tulang tibia dewasa lebih tipis terutama pada sisi subkutan dan mudah robek akibatnya fraktur tibia sering mengalami dislokasi. ${ }^{2}$ Insidens terjadinya fraktur terbuka pada tulang tibia dan fibula juga tinggi. Kecepatan penyatuan fragmen fraktur kembali juga cukup lambat, terutama apabila terdapat kerusakan periosteum dan jaringan ikat disekitarnya. Fraktur tibia dan fibula pada orang dewasa sendiri sering dilaporkan menimbulkan beberapa permasalahan. Reduksi terbuka fragmen fraktur yang berat sering berhubungan dengan beberapa komplikasi seperti gangguan suplai pembuluh darah, penyembuhan kulit yang lambat akibat pembengkakan dan infeksi pasca operasi. ${ }^{2}$

Pada penelitian ini, dari bulan Februari sampai Mei 2020 ditemukan sebanyak 30 kasus fraktur kruris di RSUD Sanjiwani Gianyar. Pada penelitian ini, ditemukan bahwa pasien dengan fraktur kruris rata - rata berjenis kelamin laki - laki (56\%). Hal ini sejalan dengan penelitian lain oleh Chauhan dkk. di Tanzania Utara yang menemukan bahwa sebagian besar pasien berjenis kelamin laki - laki $(78 \%) .{ }^{12}$ Hasil penelitian ini juga sesuai dengan penelitian lain oleh Shakti dkk. di Rumah Sakit Dr.M.Djamil, Padang bahwa mayoritas fraktur kruris terjadi pada 
pasien dengan jenis kelamin laki-laki. ${ }^{13}$ Penelitian lain oleh Anandasivam dkk. yang menganalisis mengenai prevalensi fraktur tibia juga menemukan bahwa lakilaki lebih sering mengalami fraktur tibia akibat kecelakaan. ${ }^{14}$

Berdasarkan usia, kelompok usia yang paling sering mengalami fraktur kruris pada penelitian ini adalah pasien pada kelompok usia 18 - 59 tahun. Penelitian lain oleh Chauhan dkk. menemukan bahwa rerata umur pasien dengan fraktur kruris adalah 40 tahun dengan rentang usia sampel penelitian $2-90$ tahun. ${ }^{12}$ Kelompok usia yang paling sering mengalami fraktur adalah kelompok usia 21 - 30 tahun (25\%). Untuk laki laki, kelompok usia yang paling sering mengalami fraktur adalah kelompok usia 21 - 30 tahun (31\%), sedangkan pada wanita kelompok usia yang paling sering mengalami fraktur kruris adalah usia 51 60 tahun dan 61 - 70 tahun (19\%). Pada laki - laki, kejadian fraktur kruris lebih sering ditemukan pada kelompok usia muda, hal ini dikarenakan laki - laki usia muda lebih banyak mengalami fraktur akibat kecelakaan lalu lintas. Chauhan dkk. menjelaskan bahwa laki - laki pada usia muda lebih sering mengalami kecelakaan lalu lintas karena kelompok usia ini pada umumnya melakukan pekerjaan yang berisiko seperti atlet maupun sering melakukan aktivitas yang berisiko tinggi seperti mengebut, berkendara tidak mematuhi aturan maupun berkendara dibawah pengaruh alkohol. ${ }^{12}$ Studi oleh Walters dkk. menemukan bahwa fraktur tibia lebih sering terjadi pada laki - laki usia muda dan wanita pada kelompok usia yang lebih tua, sedangkan fraktur fibula lebih sering terjadi populasi muda akibat cedera. $^{8}$

Penyebab terbanyak fraktur kruris pada penelitian ini adalah kecelakaan lalu lintas sebanyak 19 orang (64\%). Hasil penelitian ini sejalan dengan penelitian oleh Chauhan dkk. yang menemukan bahwa kecelakaan lalu lintas merupakan penyebab tersering terjadinya fraktur tibia dan fibula (78\%), sedangkan kejadian jatuh merupakan penyebab tersering kedua terjadinya fraktur tibia dan fibula (13\%). ${ }^{12}$ Chauhan dkk. mendeskripsikan bahwa, untuk laki - laki penyebab utama terjadinya fraktur adalah kecelakaan lalu lintas dengan sepeda motor, sedangkan pada perempuan penyebab fraktur setara antara kecelakaan lalu lintas dan kejadian jatuh, masing - masing $30 \% .{ }^{12}$ Penelitian lain oleh Shakti dkk. juga menemukan bahwa fraktur kruris pada umumnya terjadi dengan penyebab utama cedera traumatik kerana kecelakaan lalu lintas. ${ }^{13}$ Anandasivam dkk. menemukan bahwa populasi tua lebih sering mengalami fraktur akibat jatuh, sedangkan populasi muda lebih sering mengalami fraktur karena kecelakaan lalu lintas. ${ }^{14} \mathrm{Hal}$ ini terjadi karena pada populasi tua fraktur terjadi akibat hilangnya kekuatan tulang sehingga cedera dengan energi rendah saja dapat menimbulkan fraktur, di sisi lain fraktur ekstremitas bahwa pada populasi muda dikarakteristikan oleh cedera dengan energi tinggi. ${ }^{14}$

Pada penelitian ini, jenis fraktur kruris yang paling sering ditemui adalah fraktur tibia-fibula sebanyak 21 orang (70\%), diikuti dengan fraktur tibia sebanyak 8 orang $(27 \%)$ dan fraktur fibula sebanyak 1 orang (3\%). Fraktur tibia dan fibula merupakan fraktur tulang panjang tersering dan studi yang menganalisis mengenai insidens fraktur tibia maupun fibula yang terisolasi masing sangat jarang. Penelitian oleh Wennergren dkk., fraktur tibia merupakan kejadian fraktur paling sering terjadi akibat cedera dengan energi tinggi atau kecelakaan lalu lintas. Insidens fraktur tibia diperkirakan sebesar 51,7 per 100.000 kasus per tahunnya untuk pria dan wanita. ${ }^{15}$ Adapun, insidens fraktur tibia proksimal, diafisis dan distal adalah masing - masing 26,9; 15,7; dan 9,1 per 100.000 kasus dalam setahun. Distribusi kejadian fraktur tibia pada laki - laki dan wanita seimbang, dengan predominansi wanita pada fraktur tibia proksimal sedangkan fraktur shaft tibia dan distal tibia paling sering terjadi pada laki - laki. Rerata usia pasien laki - laki yang mengalami fraktur tibia adalah 43,8 tahun sedangkan pada wanita 56,1 tahun. Jatuh merupakan mekanisme cedera utama pada fraktur tibia, sedangkan trauma kecelakaan lalu lintas merupakan penyebab kedua tersering terjadinya cedera pada fraktur tibia proksimal dan shaft tibia. ${ }^{15}$ Fraktur fibula secara umum terjadi pada pasien usia muda akibat trauma langsung pada ekstremitas bawah. ${ }^{8}$

Manajemen awal untuk fraktur tibia dan fibula adalah perawatan dan debridemen luka, pemasangan backslab, serta fiksasi eksternal dengan intramedullary nail. Penelitian terbaru menunjukkan bahwa intramedullary nail lebih superior dibanding fiksasi dengan plate maupun fiksasi eksternal. Reduksi tibia merupakan prinsip utama untuk fraktur tibia dan fibula. ${ }^{12,16}$ Fraktur shaft tibia transversal, oblique dan spiral pada umumnya ditangani secara tertutup dengan periosteum yang intak. Ketika fraktur sudah tereduksi, periosteum yang intak ini akan mempertahankan reduksi tetap stabil dan mencegah terjadinya overreduksi. Gips harus dipasang dengan baik agar fraktur yang tereduksi berada pada posisi sestabil mungkin. Pemasangan gips dimulai sampai ke lutut (dengan kaki pasien menggantung dari meja), kemudian dibentuk secara perlahan sebelum diekstensikan sampai ke paha dengan posisi lutut difleksikan dalam sudut 30 derajat. Posisi lutut setengah fleksi dapat membantu mengontrol kejadian rotasi pada lokasi fraktur. Union biasanya tercapai dalam 3 sampai 4 bulan. ${ }^{1,7,8}$ Koreksi deformitas angulasi yang inkomplit atau hilangnya kesetaraan (alignment) dapat dilakukan setelah pembengkakan sudah membaik dengan teknik cast wedging. Fraktur tibia dan fibula oblique yang tidak stabil sebaiknya dilakukan reduksi terbuka karena rentan mengalami angulasi dan pemendekan setelah reduksi tertutup, sedangkan fraktur transversal dan comminuted yang tidak stabil harus ditangani dengan prinsip gangguan minimal pada area fraktur. Insidens komplikasi sering terjadi pada fraktur tibia dan fibula seperti osteomyelitis, kekakuan sendi, cedera arteri dan saraf, delayed union, nonunion, dan malunion, sehingga pasien harus dilakukan pemantauan dengan baik. ${ }^{2,7,8}$

Keterbatasan pada penelitian ini adalah jumlah sampel yang masih sedikit sehingga dibutuhkan penelitian yang lebih lanjut dengan sampel yang lebih besar dan cakupan yang lebih luas untuk mengetahui prevalensi dan karakteristik fraktur kruris di Bali. 


\section{SIMPULAN}

Pada penelitian ini dapat disimpulkan bahwa jenis fraktur kruris yang paling banyak ditemukan adalah fraktur tibiafibula pada kelompok usia dewasa $(18-59$ tahun) dan didominasi oleh jenis kelamin laki-laki. Penyebab terbanyak fraktur kruris adalah kecelakaan lalu lintas.

\section{UCAPAN TERIMA KASIH}

Penulis mengucapkan terima kasih kepada seluruh pihak yang telah membantu penulisan penelitian ini, terutama SMF Ilmu Bedah Rumah Sakit Umum Daerah Sanjiwani, Gianyar atas kesempatan dan bimbingan yang telah diberikan.

\section{KELAYAKAN ETIK}

Pasien sudah menyetujui untuk dilibatkan pada penelitian ini dan telah memenuhi persyaratan sesuai International Committee of Medical Journal Editors (ICMJE).

\section{KONFLIK KEPENTINGAN}

Penulis menyatakan tidak terdapat konflik kepentingan (conflict of interest) pada penulisan laporan penelitian ini.

\section{PENDANAAN}

Penulis bertanggung jawab terhadap seluruh pembiayaan dalam pembuatan laporan penelitian ini.

\section{KONTRIBUSI PENULIS}

Penulis bertanggung jawab dalam pembuatan dan penulisan laporan penelitian ini.

\section{DAFTAR PUSTAKA}

1. Salter R. Textbook of Disorders and Injuries of the Musculoskeletal System. 3rd ed. Johnson EP, editor. Philadelphia: Lippincott; 2008. p.2933

2. Solomon L. Apley's System of Orthopaedics and Fractures. 9th ed. Warwick D, Nayagam S. Florida: CRC Press; 2010. p. 120-129

3. Riandini IL, Susanti R, Yanis A. Gambaran Luka Korban Kecelakaan Lalu Lintas yang dilakukan Pemeriksaan di RSUP dr. M. Djamil Padang. J Kesehat Andalas. 2015;4(2):502-8.

4. Nugroho AA, Yulianti K. Karakteristik luka pada korban kecelakaan lalu lintas di instalasi kedokteran forensik RSUP Sanglah, Denpasar Bali. E-Jurnal Medika. 2016;1-8.

5. Zhu Y, Liu S, Chen W, Liu B, Zhang F, Lv H, et al. Epidemiology of low-energy lower extremity fracture in Chinese populations aged 50 years and above. PLoS One. 2019;14(1):1-12.

6. Fouasson-Chailloux A, Gross R, Dauty M, Gadbled G, Touchais S, Le Fort M, et al. Surgical management of lower limb fractures in patients with spinal cord injury less associated with complications than non-operative management: A retrospective series of cases. J Spinal Cord Med. 2019;42(1):39-44.

7. Thompson J, Koutsogiannis P, Jahangir A. Tibia Fractures Overview [Internet]. StatPearls. 2021 [cited 10 Juli 2021]. Available from: https:// www.ncbi.nlm.nih.gov/books/NBK513267/

8. Walters B, Constant D, Anand P. Fibula Fractures [Internet]. StatPearls. 2021 [cited 10 Juli 2021]. Available from: https://www.ncbi. nlm.nih.gov/books/NBK556139/
9. Ngunde PJ, Akongnwi ACN, Mefire CA, Puis F, Gounou E, Nkfusai NC, et al. Prevalence and pattern of lower extremity injuries due to road traffic crashes in fako division, Cameroon. Pan Afr Med J. 2019;32:1-13.

10. Pan RH, Chang NT, Chu D, Hsu KF, Hsu YN, Hsu JC, et al. Epidemiology of orthopedic fractures and other injuries among inpatients admitted due to traffic accidents: A 10-year nationwide survey in Taiwan. Sci World J. 2014;32-48.

11. Gichuhi K. Injury pattern among non-fatal road traffic crash victims. East African Orthop J. 2007;1:23-5.

12. Chauhan P, Clelland SJ, Mandari FN. The epidemiology and management of tibia and fibula fractures at Kilimanjaro Christian Medical Centre (KCMC) in Northern Tanzania. Pan Afr Med J. 2016;25:171-85.

13. Shakti P. Distribusi fraktur kruris yang dirawat di rumah sakit dr. M. Djamil, Padang periode 2015-2017 [skripsi]. Padang: Fakultas Kedokteran Universitas Andalas; 2018.

14. Anandasivam NS, Russo GS, Swallow MS, Basques BA, Samuel AM, Ondeck NT, et al. Tibial shaft fracture: A large-scale study defining the injured population and associated injuries. J Clin Orthop Trauma. 2017;8(3):22531.

15. Wennergren D, Bergdahl C, Ekelund J, Juto H, Sundfeldt M, Möller M. Epidemiology and incidence of tibia fractures in the Swedish Fracture Register. Injury. 2018;49(11):2068-74.

16. Foote C, Guyat G, Vignesh K, Mundi R. Which surgical treatment for open tibial shaft fractures results in the fewest reoperations? A network meta-analysis. Clin Orthop Relat Res. 2015;473(7):2179-92. 